\title{
PROBLEMAS Y PRINCIPIOS: MICHAEL STOLLEIS (1941- 2021), CONSTRUCTOR DE HISTORIA CONSTITUCIONAL
}

\section{PROBLEMS AND PRINCIPLES: MICHAEL STOLLEIS (1941-2021), CONSTITUTIONAL HISTORY MAKER}

\author{
Ignacio Gutiérrez Gutiérrez \\ Universidad Nacional de Educación a Distancia -- UNED (Madrid)
}

Resumen: La nota necrológica de Michael Stolleis recoge su concepción de la Historia constitucional y las cualidades intelectuales y personales que hicieron de él una referencia inexcusable en la materia.

\begin{abstract}
The obituary of Michael Stolleis collects his conception of Constitutional History and the intellectual and personal qualities that made him an inexcusable reference in the matter.
\end{abstract}

Palabras clave: Michael Stolleis, Historia constitucional, Historia del Derecho, Constitución, principios constitucionales, problemas constitucionales.

Keywords: Michael Stolleis, Constitutional History, Legal History, Constitution, Constitutional Principles, Constitutional Problems

I. He tenido el honor de traducir para esta revista dos artículos de Michael Stolleis, "Europa como Comunidad de Derecho" ${ }^{\text {y }}$ "El proyecto social de la Constitución de Weimar"2. Sus editores me piden ahora, tras su fallecimiento el pasado 18 de marzo, que redacte una nota necrológica. La responsabilidad es, a la vez, abrumadora e ineludible. Resulta evidente que ningún homenaje podrá hacer justicia a su legado; pero la misma justicia impone, al menos, documentar públicamente la deuda contraída por la comunidad científica con este incomparable historiador del Derecho público.

Los lectores de esta revista especializada ya conocen, sin embargo, las obras capitales y los reconocimientos públicos que han jalonado la trayectoria académica de Michael Stolleis ${ }^{3}$. Él mismo ofreció, con su proverbial franqueza, las claves personales y circunstanciales que permiten comprenderla, por ejemplo con ocasión del Premio de la Fondazione Internazionale Eugenio Balzan 4 y, con mayor

${ }^{1}$ Historia Constitucional, $\mathrm{n}^{\circ} .10,2009$, https://doi.org/10.17811/hc.v0i10.242.

2 Historia Constiticional, ${ }^{\circ}$. 20, 2019, https://doi.org/10.17811/hc.v0i20.597.

3 La página web de "su" Instituto Max Planck de Historia europea del Derecho, ahora bajo la nueva denominación de Instituto de Historia del Derecho y Teoría del Derecho, recoge los hitos fundamentales de su vida profesional, así como la relación de sus publicaciones: 552 entradas, aunque no aparecen numeradas las recensiones, más de 300, y la docena de comentarios de jurisprudencia: https://www.rg.mpg.de/stolleis.

4 Premio Balzan 2000 per la storia del diritto dal XVI secolo ad oggi, https://www.balzan.org/it/premiati/michael-stolleis 
amplitud, en la entrevista que cierra su libro Nahes Unrecht, fernes Recht - Zur Juristischen Zeitgeschichte im 20. Jahrhundert ${ }^{5}$. Por eso me limitaré aquí a un apunte relacionado con el nombre de esta revista, Historia constitucional, que con algunas modificaciones- sirve también de rúbrica a dos de sus últimos libros, publicados en 2017. Verfassungs(ge)schichten ${ }^{6}$ recoge la ponencia debatida el año anterior en Linz dentro del grupo de trabajo que desde 2011 se reúne en la mañana previa a la apertura de las Jornadas anuales de la Vereinigung der deutschen Staatsrechtslehrer para profundizar en los Fundamenta Iuris Publici desde perspectivas filosóficas, históricas, sociológicas y teóricas. Verfassungsund Verwaltungsgeschichte - Materialien, Methodik, Fragestellungen ${ }^{7}$ se incluye, por su parte, en la colección Methodica - Einfürungen in der rechtshistorische Forschung, que ofrece orientaciones prácticas para quienes pretenden investigar algún ámbito de la Historia del Derecho, definido en términos más o menos específicos: sobre las fuentes y la literatura secundaria, sobre los métodos, el status quaestionis y las dudas subsistentes. En tales contextos recupera Stolleis algunas de sus reflexiones metodológicas generales sobre la Historia del Derecho como ciencia, ya difundidas en castellano ${ }^{8}$, y las proyecta sobre el ámbito de la Historia constitucional ${ }^{9}$.

Para escribir Historia, dice Stolleis, resulta determinante escudriñar el uso de las palabras, en el que estas cobran significado. Por eso considera relevante la trayectoria que discurre desde la inicial Reichshistorie, pasando por la voluntarista agrupación de la información referida a los distintos Estados alemanes en una Historia alemana del Derecho y del Estado (Karl Frierdrich Eichhorn, 1808-1823), hasta la Historia constitucional alemana de Georg Waitz (1844). Así, resulta que "el nacimiento de la Historia constitucional clásica en el siglo XIX ocurrió justamente en la época del clásico Estado nacional. Pero su tiempo ha pasado"; "los Estados nacionales europeos ya han empezado a declinar como conceptos ordenadores".

Y, sin embargo, un determinado concepto formal de Constitución no puede limitar, a su juicio, la perspectiva de los historiadores. La Historia constitucional es simplemente la parte de la Historia del Derecho que se ocupa de la determinación jurídica de las estructuras e instituciones fundamentales del poder público. Tanto esas estructuras como sus formas de juridificación, en su configuración actual, evocan tiempos a veces remotos; y son precisamente las circunstancias del presente las que explican tanto la creciente inclinación de los profesores de Derecho público hacia los fundamentos de su disciplina como su interés por anclarlos en una Historia del Derecho de amplio recorrido. Así, cuando hoy nos preguntamos por el orden público nacional, europeo e

5 Wallstein, Göttingen, 2014, págs. 135 ss. En el marco de una publicación del Jena Center Geschichte des 20. Jahrhunderts dirigido por Norbert Frei, la entrevista lleva un título significativo: "Rechtshistoriker sind Historiker" - Ein Gespräch über Väter, Bildungswege und Zeitgenossenschaft.

6 Mohr - Siebeck, Tübingen, 2017; el libro recoge también el texto de los comentarios a la ponencia expuestos en aquella sesión por Christoph Gusy y Anna-Bettina Kaiser.

7 De Gruyter/Oldenbourg, Berlin, 2017.

8 “Escribir Historia del Derecho: ¿reconstrucción, narración o ficción?”, en Michael Stolleis, La Historia del Derecho como obra de arte, Comares, Granada, 2009, págs. 1 ss.

$9 \mathrm{Me}$ apoyo también en "La 'casa europea' y su constitución”, en M. Stolleis, La Historia del Derecho como obra de arte, op. cit., pp. 63 ss. 
internacional, la conciencia de la textura histórica de las formas politicas trae a la memoria el Imperio alemán, sobre cuyo anómalo perfil no cabía fundar una teoría del Estado coherente, e incluso la Confederación Germánica"10. "Resulta indudablemente grande el significado de los dos siglos transcurridos desde la Revolución francesa para la formación del Estado constitucional moderno de corte occidental; pero, en la misma medida, no es posible renunciar a su anclaje en las épocas más antiguas". Los antecedentes que pueden rastrearse para los singulares elementos que luego se agregan en el Estado constitucional tienen un significado decisivo: "anclar la cultura política en la Historia, su paulatina anidación en el subconsciente, la progresiva transformación de las costumbres apoyadas en el consenso general en indicaciones normativas no escritas - esto es lo que (...) determina el funcionamiento cotidiano de una comunidad y la ética pública que se practica, mucho más que el Derecho constitucional y legal".

De acuerdo con eso, la consideración histórica ya no llevaría a preguntarse necesariamente por "la" Constitución en singular, en términos que pondrian en primer plano un tipo ideal determinado por la correlación entre orden político unitario (estatal) y Constitución. Importa más, a su juicio, conocer la función que han tenido en la Historia, por ejemplo, el postulado del estado de Derecho o el principio de la división de poderes, y preguntarse por la nueva configuración que han de adoptar para conservarla. Porque lo decisivo no es la pervivencia del Estado, sino que sigan existiendo garantías eficaces de la libertad frente al poder, o también instituciones que proporcionen ciertos servicios (policia, Derecho penal, justicia, procura existencial, educación y cultura, impuestos y finanzas públicas ...). Corresponde al Derecho constitucional, en definitiva, la búsqueda de respuestas acordes con los clásicos principios constitucionales (materiales e institucionales) para los problemas de naturaleza constitucional. Y por eso también cabe preguntarse por la "trayectoria del Estado constitucional con la perspectiva de la globalización"11.

II. Sobre estas consideraciones de Stolleis apoyé mi proyecto de analizar el debate doctrinal alemán acerca de la posibilidad de aplicar la idea de Constitución más allá del Estado nacional, con la consiguiente transformación del significado del término, determinada por la ampliación de su contexto de uso. Porque, del mismo modo que es posible identificar en el pasado diversos conceptos de Constitución, también ahora pueden diferenciarse los usos y significados de una palabra con los que se pretende hacer justicia al legado histórico que condensa y a las expectativas que evoca, pero también a las profundas transformaciones que hoy experimentan las realidades politicas y los sistemas jurídicos. Esa pluralidad se refleja asimismo en el uso diferenciado de otros términos de la misma familia léxica, como constitucionalismo, constitucionalización o constitucional.

Mi trabajo se desarrolló fundamentalmente en Frankfurt (octubre y noviembre de 2006), durante una estancia investigadora financiada por el Instituto que él dirigía. Yo había conocido a Michael Stolleis dos años antes, el 15 de noviembre de 2004; la cita que le había pedido para comentar el borrador de

10 Michael Stolleis, La textura histórica de las formas politicas, Marcial Pons, Madrid/Barcelona, 2011 .

11 En Michael Stolleis, Andreas Paulus, Ignacio Gutiérrez, El Derecho constitucional de la globalización, Fundación Coloquio Jurídico Europeo, Madrid, 2013, págs. 23 ss. 
mi recensión al tercer volumen de su Historia del Derecho público en Alemania ${ }^{12}$ se convirtió aquel día, para mi sorpresa, en una conversación de cuatro horas. Mi primer reencuentro con él, el 2 de octubre de 2006, coincidió con su discretísima despedida como director del Instituto, formalizada en un acto estrictamente interno con breves discursos, vino y frankfurter Kranz (aunque siguió activo allí no solo como investigador, sino también asumiendo la dirección provisional durante más de dos años, entre 2007 y 2009, con motivo de la enfermedad y la muerte de la directora Marie Theres Fögen). Diez dias después, el 12 de octubre de 2006, asistí por primera vez a una conferencia suya, impartida en Wetzlar por invitación de la Gesellschaft für Reichskammergerichtsforschung ${ }^{13}$.

Las impresiones de aquellos primeros contactos se han quedado grabadas en la memoria, quizá porque se vieron confirmadas una y otra vez. Llamaba la atención su cordialidad jovial y seductora, una sencillez ajena a las formalidades que cabía esperar de un ilustre catedrático alemán; también su cercanía y empatía, con acusada sensibilidad hacia las circunstancias y los problemas personales; su extrema humildad, eludiendo el lugar de honor que, sin embargo, inevitablemente ocupaba, porque le correspondía allí donde se encontrara. También su magisterio resultaba cercano, discreto, casi involuntario, simple emanación de la autoridad que encarnaban sus palabras; porque siempre, y eso es lo decisivo para explicar el reconocimiento alcanzado por su obra, acreditaba rigor y responsabilidad intelectual en grado extremo, una exigencia sobre sí mismo que también bloqueaba el brote de cualquier frivolidad en el entorno. Ese compromiso moral (¡y estilístico!) con su obra se acompañaba de una disciplina de trabajo implacable y eficacísima; solo así se comprende la amplitud y riqueza de sus publicaciones, capaces de integrar además el más diverso catálogo de estímulos (literarios y gráficos, simbólicos y económicos, filosóficos y mitológicos...). A todo ello hay que añadir la objetividad y capacidad resolutiva con la que abordada las cuestiones prácticas; su empeño en la organización y promoción de investigaciones y seminarios elevaron a Frankfurt a la capitalidad europea de la Historia del Derecho.

Algunas de esas cualidades podrian corroborarlas también el secretario de esta Revista, Leonardo Álvarez, que junto con María Valvidades fue invitado en 2008 al Curso de Verano anual organizado por el Max-Planck-Institut de Historia europea del Derecho de Frankfurt para promover el contacto entre jóvenes investigadores; o su director, Ignacio Fernández Sarasola, que conoció a Michael Stolleis con motivo del Seminario Internacional Mecanismos de exclusión en la democracia de partidos celebrado en Madrid el 5 de abril de 2017, en el que ambos fueron ponentes. El privilegio de haber podido mediar así en la proyección de Michael Stolleis sobre España, a través de traducciones y también facilitando

12 La serie completa alcanzó cuatro volúmenes: Geschichte des öffentlichen Rechts in Deutschland, C.H. Beck, München, 1988 (1600-1800), 1992 (1800-1914), 1999 (1914-1945), 2012 (1945-1990). Una versión muy condensada, Öffentliches Recht in Deutschland. Eine Einführung in seine Geschichte (16.-21. Jahrhundert), C.H. Beck, München, 2014, está disponible en castellano: Introducción al Derecho público alemán (siglos XVI-XXI), Marcial Pons, Madrid, 2018.

13 Heiliges Römisches Reich deutscher Nation, Deutsches Reich, "Drittes Reich" - Transformation und Destruktion einer politischen Idee, Gesellschaft für Reichskammergerichtsforschung, Wetzlar, 2007 ("Sacro Romano Imperio de la Nación Alemana, Reich alemán, Tercer Reich - Transformación y destrucción de una idea politica", en Michael Stolleis, La textura histórica de las formas politicas, op. cit., pp. 75 ss.). 
PROBLEMAS Y PRINCIPIOS: MICHAEL STOLLEIS (1941- 2021), CONSTRUCTOR...

relaciones personales como estas, está entre mis mayores satisfacciones profesionales. Porque Michael Stolleis fue un historiador, jurista y académico excepcional, un ejemplo eminentísimo y admirable de lo que sus propias tesis formulan: si el pasado solo es accesible en su comunicación, son los historiadores quienes construyen, al escribirla, la Historia de la que hoy nos nutrimos.

Enviado el (Submission Date): 26/04/2021

Aceptado el (Acceptance Date): 5/05/2021 